NBER WORKING PAPER SERIES

\title{
CONSUMPTION SMOOTHING AND THE WELFARE CONSEQUENCES OF SOCIAL INSURANCE IN DEVELOPING ECONOMIES
}

\author{
Raj Chetty \\ Adam Looney \\ Working Paper 11709 \\ http://www.nber.org/papers/w11709 \\ NATIONAL BUREAU OF ECONOMIC RESEARCH \\ 1050 Massachusetts Avenue \\ Cambridge, MA 02138 \\ October 2005
}

We have benefited from comments by Roger Gordon, Ted Miguel, and seminar participants at the NBER East Asian Seminar. The analysis and conclusions set forth are those of the authors and do not indicate concurrence by other members of the research staff or the Board of Governors of the Federal Reserve. The views expressed herein are those of the author(s) and do not necessarily reflect the views of the National Bureau of Economic Research.

(C)2005 by Raj Chetty and Adam Looney. All rights reserved. Short sections of text, not to exceed two paragraphs, may be quoted without explicit permission provided that full credit, including () notice, is given to the source. 
Consumption Smoothing and the Welfare Consequences of Social Insurance in Developing Economies

Raj Chetty and Adam Looney

NBER Working Paper No. 11709

October 2005

JEL No. H0

\begin{abstract}
$\underline{\text { ABSTRACT }}$
Studies of risk in developing economies have focused on consumption fluctuations as a measure of the value of insurance. A common view in the literature is that the welfare costs of risk and benefits of social insurance are small if income shocks do not cause large consumption fluctuations. We present a simple model showing that this conclusion is incorrect if the consumption path is smooth because individuals are highly risk averse. Empirical studies find that many households in developing countries rely on inefficient methods to smooth consumption, suggesting that they are indeed quite risk averse. Hence, social safety nets may be valuable in low-income economies even when consumption is not very sensitive to shocks.
\end{abstract}

\author{
Raj Chetty \\ Department of Economics \\ UC- Berkeley \\ 521 Evans Hall \#3880 \\ Berkeley, CA 94720 \\ and NBER \\ chetty@econ.berkeley.edu \\ Adam Looney \\ Federal Reserve Board \\ 20th Street and Constitution Ave. \\ Washington, DC 20551 \\ adam.looney@frb.gov
}




\section{Introduction}

Government policies differ systematically between poorer and richer countries. One striking difference is the much smaller weight given to social insurance programs in low-income economies (see Figure 1). In 1996, the average expenditure on social insurance as a fraction of GDP in countries with below-median per capita income was 6.8 percent; the corresponding figure in above-median countries was 18.5 percent. Social insurance spending as a fraction of government expenditure is also significantly higher in higher income economies. ${ }^{1}$

A large literature has examined the potential value of social insurance in developing economies by estimating the effects of income shocks on household consumption. The presumption underlying this literature is that the welfare costs of risk, and therefore the benefits of social insurance, are determined by the extent to which income shocks cause fluctuations in consumption. A common view is that if consumption does not fluctuate very much to begin with, the potential welfare gains from smoothing consumption further through social insurance must be quite small. Morduch (1995) remarks that, "The emerging consensus of the empirical literature [on consumption-smoothing in developing economies] is that holes in effective [consumption] insurance exist... But, in general, the holes are a good deal smaller than many had assumed... The results have clear policy implications. [If] markets and alternative mechanisms do indeed provide reasonably good insurance and credit, publicly provided financial services and social security could crowd out private efforts with limited net gain to society." The consensus on the empirical evidence has eroded somewhat since Morduch's review. More recent empirical studies have pointed out that consumption drops may be larger, especially among vulnerable subgroups such as the poor (Ravallion and Chaudhuri 1997, Morduch 1999). However, the general view that consumption fluctuations

\footnotetext{
${ }^{1}$ See Chetty and Looney (2005) for additional details. For these figures, social insurance is defined as total expenditures on social security, disability insurance, unemployment insurance, insurance against work-related injuries, and government provided health insurance. The source for these statistics is the International Labour Organization (2000).
} 
give a measure of the value of additional insurance remains prevalent (see Gertler and Gruber 2002, Fafchamps 2003, and Cameron and Worswick 2003 for recent examples).

In this paper, we re-examine whether empirical results about risk and consumption fluctuations have clear policy implications. In particular, we show that the welfare gains from increasing insurance cannot be directly inferred from the size of consumption drops. Indeed, the value of insurance may be very large even in environments where consumption does not fluctuate much. To see the basic idea underlying our argument, consider two economies where agents face transitory income shocks. In the first case (a rich country), agents have access to credit markets and networks that allow them to smooth consumption easily when hit by a shock. In the second economy (a poor country), private market insurance is very limited. However, households are close to a subsistence level of consumption, and are very reluctant to cut consumption further when their income falls for fear of starvation. These risk-averse households therefore use whatever methods they can to avoid a substantial consumption drop (e.g. taking children out of school). In both of these cases, an econometrician would observe a smooth consumption path in the data. However, in the latter case - where the smoothness of consumption is the result of high risk aversion and not efficient private insurance markets - social insurance could yield large welfare gains. Intuitively, these welfare gains arise from reduced reliance on costly consumption-smoothing mechanisms, leading to improvements such as greater education for children.

To formalize this idea, we adopt from the public finance literature a normative model of social insurance developed in Baily (1978) and Chetty (2005). These studies show that the welfare gain from social insurance (ignoring efficiency costs caused by distortions in behavior) is determined by the product of the percentage consumption drop caused by the shock $\left(\frac{\Delta c}{c}\right)$ with the coefficient of relative risk aversion $(\gamma)$ in a general class of stochastic dynamic models. Hence, holding $\gamma$ fixed, a smoother consumption path (smaller $\frac{\Delta c}{c}$ ) does in fact imply smaller welfare gains from social insurance. However, it is important to note that $\gamma$ and $\frac{\Delta c}{c}$ are inversely related. Highly risk averse households should be willing to take 
extremely costly measures to insure a smooth consumption path. Therefore, in order to understand whether a social safety net is valuable, one must determine the reason that $\frac{\Delta c}{c}$ is small. If it is small because agents have good private insurance (as in the rich country example above), social insurance may indeed be unnecessary. But if $\frac{\Delta c}{c}$ is small because $\gamma$ is large (as in the poor country example), small consumption fluctuations may belie large welfare gains from insurance because the product $\gamma \frac{\Delta c}{c}$ could be quite large.

This result has practical relevance because many households in low-income countries are close to a subsistence level of consumption and are forced to cut back on consumption of basic necessities when their income falls. It is therefore plausible that consumption drops greatly reduce welfare for these households, implying that $\gamma$ is high. Consistent with this claim, several studies (reviewed in section 3) have found that households in low-income economies take very costly measures to avoid income risk and maintain consumption in the face of income shocks, such as reducing expenditures on children's education, putting other household members into work, planting lower-risk but lower-yielding crops, or even, as found by Miguel (2005), murdering elderly dependents. These results indicate that social insurance could provide greater welfare gains than suggested by prior work even if consumption is smooth in low-income economies.

It should be noted that the value of social safety nets in reducing the extent of such inefficient behaviors has been recognized in prior work (see e.g. Rosenzweig and Binswanger 1993, Rosenzweig and Wolpin 1993, Morduch 1999). In fact, the World Bank's "social risk management" approach to social protection considers the costs of coping strategies in determining the value of safety nets (Holzmann et. al. 2003) . However, existing studies do not formally link this point to results from the consumption-smoothing literature as we do here. This formal link is useful in clarifying how evidence on consumption smoothing and costly behaviors can be combined to obtain a more precise understanding of the welfare consequences of social insurance.

It is important to keep in mind that the efficiency costs of social insurance - e.g., reduced 
employment or opportunity costs such as forgone infrastructure or health investments may be very large. Since we do not discuss these costs here, one cannot directly conclude from the results that introducing a large safety net will raise net welfare. Hence, the most important lesson of this study is simply that small consumption fluctuations need not imply that existing insurance is "adequate" in developing economies. In fact, the converse may be true: consumption may be smooth precisely because the welfare costs of consumption fluctuations are very high.

The remainder of the paper proceeds as follows. The next section sketches a simple model of income shocks and derives a formula for the welfare gains from social insurance following Chetty (2005). Section 3 shows how small consumption fluctuations can arise from either good private insurance or high risk aversion, with very different implications for optimal policy. Section 4 offers concluding remarks.

\section{A Normative Framework}

We derive a formula for the marginal welfare gain from implementing a social insurance program in a highly stylized model. The simplicity of the model is purely for expositional ease; as we discuss below, the formula that we obtain actually holds in a very general class of dynamic models.

Consider a static expected utility model of income shocks. Suppose the agent has utility over consumption $u(c)$. Let the disutility of obtaining $\$ c$ of consumption be given by a linear function

$$
\psi(c)=\theta c
$$

A negative shock - such as bad weather, illness, crop damage, or unemployment - can be modeled in this framework as an increase in $\theta$, which makes earning money more difficult. In the good state, $\theta$ captures the disutility of effort required to generate income under normal 
conditions. In the bad state, $\theta$ rises because generating $\$ c$ of consumption requires more costly activities such as planting new crops, searching for another job, increasing labor supply of other household members, reducing human capital or health investments in children.

To simplify the notation, suppose that there are two states (good rainfall and bad rainfall), with $\theta_{b}>\theta_{g}=1$. With this normalization, $\theta_{b}$ can be interpreted as how much more difficult it is to earn money in the bad state than the good state. For example, $\theta_{b}=2$ implies that the disutility of generating consumption is doubled when there is little rain. Let $p$ denote the probability that the bad state occurs.

In this model, consumption will generally differ in the bad state and the good state if private insurance markets are incomplete. Let $c_{b}$ denote consumption in the bad state and $c_{g}$ consumption in the good state. An actuarially fair insurance program that raises $c_{b}$ by $\$ 1$ must lower $c_{g}$ by $\frac{p}{1-p}$. The marginal welfare gain from this program is given by

$$
\widetilde{W}=p u^{\prime}\left(c_{b}\right)-(1-p) \frac{p}{1-p} u^{\prime}\left(c_{g}\right)=p\left(u^{\prime}\left(c_{b}\right)-u^{\prime}\left(c_{g}\right)\right)
$$

This measure has no cardinal interpretation since preferences are unique only up to an affine transformation of $u$. One intuitive way to convert this expression to a money metric is to normalize this welfare gain by the welfare change from a $\$ 1$ increase in consumption in the good state, which equals $(1-p) u^{\prime}\left(c_{g}\right)$. Holding $p$ fixed, the welfare gain from social insurance relative to an increase in income in the good state is thus proportional to

$$
W=\frac{u^{\prime}\left(c_{b}\right)-u^{\prime}\left(c_{g}\right)}{u^{\prime}\left(c_{g}\right)}
$$

To simplify this expression, take a Taylor approximation to the utility function and write

$$
\begin{aligned}
W & \simeq-\frac{u^{\prime \prime}\left(c_{g}\right)}{u^{\prime}\left(c_{g}\right)}\left(c_{g}-c_{b}\right) \\
& =\gamma \frac{\Delta c}{c}
\end{aligned}
$$


where $\frac{\Delta c}{c}=\frac{c_{g}-c_{b}}{c_{b}}$ is the average observed consumption drop, and $\gamma=-\frac{u^{\prime \prime}}{u \prime} c_{g}$ is the coefficient of relative risk aversion. The intuition for this formula is straightforward: The marginal welfare gain from $\$ 1$ of insurance (or, conversely, the welfare cost of an income shock) depends on the size of consumption fluctuations $\left(\frac{\Delta c}{c}\right)$ and the utility value of having a smoother consumption path $(\gamma)$.

This simple formula holds in a much more general setting than the model above. Chetty (2005) analyzes a general dynamic lifecycle model where agents maximize expected lifetime utility and face income shocks based on an arbitrary stochastic process. Agents have utility over consumption and $N$ other arbitrary choice variables and face $M$ arbitrary constraints (e.g. borrowing constraints) in making their decisions. In this environment, Chetty shows that the marginal benefit of social insurance is given precisely by (1) under some weak regularity conditions. It follows that this result applies even in the presence of informal insurance arrangements, credit constraints, or non-traditional assets such as livestock (as in Rosenzweig and Wolpin, 1993). This is because individual optimization and the envelope theorem guarantee that at the margin, other behavioral responses and constraints have no first-order effects on welfare (see Chetty 2005 for details). Hence, (1) provides a robust guide for welfare analysis.

The next section uses this formula to examine the relationship between the size of the consumption drop $\left(\frac{\Delta c}{c}\right)$ and the welfare gain from social insurance $(W)$.

\section{How Large is the Welfare Gain from Insurance?}

Starting with Cochrane (1991) and Townsend (1994), a large literature has tested whether private insurance markets are complete. These studies estimate $\frac{\Delta c}{c}$ by examining the effect of idiosyncratic shocks such as job loss, health changes, or weather shocks on consumption growth. Townsend's study of Indian farmers and other subsequent studies find that $\frac{\Delta c}{c}$ is in the range of 10-15 percent for moderate-sized temporary shocks in developing economies 
(Deaton 1992, Paxson 1992, Chetty and Looney 2005). In contrast, Ravallion and Chaudhuri (1997) argue that Townsend's methods understate the true size of consumption drops because of measurement error and other econometric problems. Jalan and Ravallion (1999) find that the size of consumption drops varies sharply across income groups, with much larger drops among the poorest households. While empirical results vary, the important point is that evidence of small consumption fluctuations is uniformly taken to imply that the welfare cost of income risk is low. Hence, the general presumption is that the potential welfare gain from social insurance against transitory income shocks is limited if $\frac{\Delta c}{c}$ is small (see e.g. Morduch 1995, Cameron and Worswick 2003).

The formula derived above shows that $\frac{\Delta c}{c}$ is only one parameter that determines the benefits of social insurance. The marginal welfare gain from insurance depends on the product of $\gamma$ and $\frac{\Delta c}{c}$. This observation is important because $\gamma$ and $\frac{\Delta c}{c}$ are inversely related it is precisely in situations where $\gamma$ is high that agents will try to keep $\frac{\Delta c}{c}$ small. To see the normative consequences of this point, consider a parametric example of the model outlined above. Suppose the agent has CRRA utility over consumption in each state:

$$
u(c)=\frac{c^{1-\gamma}}{1-\gamma}
$$

In this setting, the worker chooses consumption in each state by solving

$$
\max _{c} \frac{c^{1-\gamma}}{1-\gamma}-\theta c
$$

Hence

$$
c^{*}(\theta)=\theta^{-1 / \gamma}
$$

The consumption drop from the good to bad state is therefore

$$
\frac{\Delta c}{c}=\frac{c_{g}-c_{b}}{c_{g}}=1-\frac{c_{b}}{c_{g}}=1-\left(\frac{1}{\theta_{b}}\right)^{1 / \gamma}
$$


This expression shows that $\frac{\Delta c}{c}$ is decreasing in $\gamma$ and increasing in $\theta_{b}$. Intuitively, high $\gamma$ makes consumption reductions particularly costly, and the agent therefore exerts greater effort in the bad state to maintain consumption close to $c_{g}$. Similarly, high $\theta_{b}$ makes earning income in the bad state particularly costly, making it preferable to tolerate a larger consumption drop. These comparative statics indicate that the $\frac{\Delta c}{c}$ observed in developing economies could be small for two independent reasons: (1) $\theta_{b}$ is low, i.e. agents are able to easily and inexpensively smooth consumption by borrowing or through informal insurance mechanisms or (2) $\gamma$ is high, i.e. agents are very risk averse to fluctuations and work hard to have a small consumption drop even though $\theta_{b}$ might be high. In case 1 , the marginal welfare gain from social insurance $\gamma \frac{\Delta c}{c}$ is likely to be small. In contrast, in case 2 , the gain from social insurance could be quite large even if $\frac{\Delta c}{c}$ is small because $\gamma$ may be very high.

Table 1 illustrates this point quantitatively by showing simulations of the implied consumption drop and welfare gain for a range of $\gamma$ and $\theta_{b}$. Part A of the Table shows that a relatively small consumption drop of $\frac{\Delta c}{c} \approx 10-15$ percent can be generated by a variety of combinations of $\gamma$ and $\theta_{b}$, indicated in bold on the diagonal of the table. Part B shows that the welfare implications implied by the different combinations above can vary widely. With high $\gamma$ and $\theta_{b}$, the marginal gain in expected utility from the provision of an extra dollar of social insurance can be three times as large as the gain with low $\gamma$ and $\theta_{b}$.

To understand this point intuitively, consider two different descriptions of an economy, both of which could generate a consumption drop of 10 percent. In the first scenario (low $\gamma$, low $\theta_{b}$ ), agents have access to credit markets and informal village-level networks that allow them to smooth consumption easily when hit by a shock. In this case, a mandated social insurance program would simply crowd out existing private market arrangements, with little net welfare gain. In the second scenario (high $\gamma$, high $\theta_{b}$ ), private market insurance arrangements are very poor. However, households are close to a subsistence level of consumption even in the good state and are therefore very reluctant to cut consumption further when they are hit by a shock. They therefore use costly, high $\theta$, methods to avoid a substantial 
consumption drop, such as taking children out of school or sending additional households members into the labor force. In the second scenario, the provision of social insurance could yield large welfare gains despite the smoothness of consumption, because such programs reduce reliance on costly consumption-smoothing mechanisms when hit by shocks.

Which of these two scenarios for consumption smoothness actually applies to developing economies? Although formal empirical tests to answer this question are outside the scope of this paper, it is worth briefly reviewing some existing work that provides suggestive evidence on this issue. First, several studies have found that households reduce consumption of necessities such as rice and other staples when income falls (Beegle, Frankenberg, and Thomas 2000, Frankenberg, Smith, and Thomas 2003, Chetty and Looney 2005). Consumption of these goods would presumably be reduced only in the most dire straits, suggesting that marginal utility must rise sharply as consumption falls for these households.

Second, studies that examine how people cope with income risk provide information about risk aversion. These studies, which are reviewed in Dercon (2002) and Fafchamps (2003), generally find that households often use costly (high $\theta$ ) methods to smooth income and smooth consumption. Frankenberg, Thomas, Beegle (1999), Thomas et. al. (2004), and Chetty and Looney (2005) find that households reduce spending on children's education to mitigate unemployment shocks. Kochar (1999), Beegle, Frankenberg, Thomas (2000), Cameron and Worswick (2003), Frankenberg, Smith, and Thomas (2003) document sizable labor supply responses to mitigate income losses. Perhaps most strikingly, Miguel (2005) reports evidence suggesting that some households resort to murder of elderly dependents ("witches") to smooth temporary income losses caused by droughts. There is also evidence that households take measures ex-ante to avoid risk. Rosenzweig and Binswanger (1993) show that poor households in India adopt less risky farming methods at considerable expense to farm profitability. Rosenzweig and Stark (1989) argue that Indian families marry their daughters to grooms in distant villages as an insurance mechanism.

Based on the model, this evidence that households resort to costly smoothing methods 
suggests that $\gamma$ is high. Intuitively, if households are willing to take very costly measures to maintain consumption when income falls, they must be very averse to a reduction in consumption. Miguel's findings are a particularly provocative example of this point: if households "smooth" consumption by killing dependents whom they identify as "witches," then the benefits of insurance would clearly be large even if $\frac{\Delta c}{c}$ is small.

In short, much of the existing evidence on behavioral responses to shocks point in favor of the high $\gamma$ explanation in situations where consumption is truly smooth. If risk aversion is indeed as high as these studies suggest, social insurance could have substantial welfare benefits in developing economies. While the evidence reviewed above does not definitively prove that $\gamma$ is high, it at least suggests that this possibility deserves careful examination.

\section{Conclusion}

This paper has shown how existing reduced-form empirical results from the development literature can be used in a simple but general normative framework to evaluate the benefits of social insurance. The central lesson that emerges from this analysis is that estimates of the consumption fluctuations associated with shocks are inadequate to compute the welfare gains from social insurance. It is equally important to determine the motives and mechanisms of consumption smoothing - good private or informal insurance markets (low $\theta_{b}$ ) or high risk aversion (high $\gamma$ )?

While further research on this issue is needed before drawing firm policy conclusions, existing evidence on smoothing mechanisms suggests that at least some households in developing economies are highly risk averse. Hence, provision of social insurance could raise welfare by reducing inefficient behaviors ex-ante and ex-post. Importantly, implementing some types of social insurance may be feasible without introducing significant moral hazard costs. For instance, detailed local data on weather is already collected in many low-income countries (e.g. through the African Famine Early Warning System). If the costs of creating 
an insurance program that transfers funds on the basis of objective weather measures are small, such a system could offer significant welfare gains. 


\section{References}

Baily, Martin, "Some Aspects of Optimal Unemployment Insurance," Journal of Public Economics 10 (1978), 379-402.

Beegle K, Frankenberg E, Thomas D. 2000. "Labor Market Transitions of Men and Women During an Economic Crisis: Evidence from Indonesia." Rand Labor and Population Working Paper 00-11.

Binswanger, Hans P., "Attitudes Toward Risk: Theoretical Implications of an Experiment in Rural India," Economic Journal, 91, December 1981, 867-890

Cameron, L. and C. Worswick 2003. "The Labor Market as a Smoothing Device: Labor Supply Responses to Crop Loss", Review of Development Economics,7(2), 327-341.

Chetty, Raj, "A General Formula for the Optimal Level of Social Insurance," UC Berkeley mimeo, 2005.

Chetty, Raj and Adam Looney, "Income Risk and the Benefits of Social Insurance: Evidence from Indonesia and the United States," NBER working paper 11708, 2005.

Cochrane, John H, "A Simple Test of Consumption Insurance." Journal of Political Economy 99 (1991), 957-76.

Deaton, Angus. "Saving and Income Smoothing in Côte d'Ivoire," Journal of African Economies, 1992, v. 1, iss. 1, pp. 1-24.

Dercon, S. "Income Risk, Coping Strategies, and Safety Nets," The World Bank Research Observer, vol. 17, no. 2 (Fall 2002), pp. 141-166.

Fafchamps, Marcel. Rural Poverty, Risk, and Development, Elgar Publishing, December, 2003.

Frankenberg E, Thomas D, Beegle K. 1999. "The Real Costs of Indonesia's Economic Crisis: Preliminary Findings from the Indonesia Family Life Surveys." DRU-2064NIA/NICHD. Santa Monica, CA: RAND.

Frankenberg, E, Smith, J, and Thomas, D. 2003. Economic shocks, wealth and welfare, Journal of Human Resources, 38.2: 280-321.

Gertler, P. and J. Gruber, "Insuring Consumption Against Illness," The American Economic Review, March (2002), vol. 92, no. 1, pp. 51-70(20).

Gertler, P., E. Moretti, and D. Levine "Do Microfinance Programs Help Families Insure Consumption Against Illness?" UC-Berkeley mimeo, 2001.

Holzmann, Robert and Steen Jørgensen. "Social Risk Management: A New Conceptual Framework for Social Protection, and Beyond," International Tax and Public Finance, 8(4), August, 2001, 529-556.

Holzmann, R., L. Sherburne-Benz, and E. Tesliuc. 2003. "Social Risk Management: The World Bank's Approach to Social Protection in a Globalizing World," World Bank, Washington D.C.

International Labour Organization, World Labour Report 2000: Income Security and Social Protection in a Changing World, 2000. 
Jalan, Jyotsana and M. Ravallion, 1999 "Are the poor less well insured? Evidence on vulnerability to income risk in rural China." Journal of Development Economics 58(1): 61-81.

Kochar, Anjini. "Smoothing Consumption by Smoothing Income: Hours-of-Work Responses to Idiosyncratic Agricultural Shocks in Rural India," The Review of Economics and Statistics, February 1999, 81(1):50-61.

Miguel, Edward, 2005. "Poverty and Witch Killing," Review of Economic Studies, forthcoming.

Morduch, Jonathan, 1995. "Income Smoothing and Consumption Smoothing." Journal of Economic Perspectives, 9(3) 103-114.

Morduch, Jonathan, "Between the State and the Market: Can Informal Insurance Patch the Safety Net?" The World Bank Research Observer, vol. 14, no. 2 (August 1999), pp. 187-207.

Paxson, C. "Using Weather Variability to Estimate the Response of Savings to Transitory Income in Thailand," The American Economic Review, Vol. 82, No. 1. (Mar., 1992), pp. $15-33$.

Ravallion, M. 1997. "Famines and Economics," Journal of Economic Literature, 35(3), 1205-1242.

Ravallion, M. and S. Chaudhuri, "Risk and Insurance in Village India: Comment," Econometrica, 65(1), Jan., 1997, 171-184.

Rosenzweig, M. and H. Binswanger. "Wealth, Weather Risk and the Composition and Profitability of Agricultural Investments," The Economic Journal, Vol. 103, No. 146, January 1993, 56-78.

Rosenzweig, M. and K. Wolpin, "Credit Market Constraints, Consumption Smoothing, and the Accumulation of Durable Production Assets in Low-Income Countries: Investments in Bullocks in India," Journal of Political Economy 101(2), 223-255, 1993.

Rosenzweig, M. and O. Stark. "Consumption Smoothing, Migration, and Marriage: Evidence from Rural India." The Journal of Political Economy, Vol. 97, No. 4 (Aug., 1989), 905-926.

Thomas D, Beegle K, Frankenberg E, Sikoki B, Strauss J, Teruel G. 2004. "Education in a Crisis." Journal of Development Economics, 74(1): 53-85.

Townsend, Robert, "Risk and Insurance in Village India", Econometrica, 62(3), May 1994, 539-591. 
Table 1

CALIBRATIONS OF CONSUMPTION DROP AND WELFARE GAINS OF SOCIAL INSURANCE

\begin{tabular}{ccccccc} 
& \multicolumn{5}{c}{ A. Consumption Drop $(\Delta \mathbf{c} / \mathbf{c})$} \\
\cline { 3 - 7 } & & 1 & \multicolumn{5}{c}{ Coefficient } & \\
& & 1 & 2 & 3 & 4 & 5 \\
\cline { 3 - 7 } & 0.00 & 0.00 & 0.00 & 0.00 & 0.00 \\
Disutility of & 1.25 & 0.20 & $\mathbf{0 . 1 1}$ & 0.07 & 0.05 & 0.04 \\
effort in unemp. & 1.5 & 0.33 & 0.18 & $\mathbf{0 . 1 3}$ & 0.10 & 0.08 \\
state $\left(\theta_{\mathbf{b}}\right)$ & 1.75 & 0.43 & 0.24 & 0.17 & $\mathbf{0 . 1 3}$ & 0.11 \\
& 2 & 0.50 & 0.29 & 0.21 & 0.16 & $\mathbf{0 . 1 3}$
\end{tabular}

\section{B. Marginal Welfare Gain $(\gamma \Delta \mathrm{c} / \mathrm{c})$}

\begin{tabular}{ccccccc}
\multicolumn{1}{c}{} & \multicolumn{5}{c}{ Coefficient of relative risk aversion $(\gamma)$} \\
\cline { 3 - 7 } & & 1 & 2 & 3 & 4 & 5 \\
\hline Disutility of & 1 & 0.00 & 0.00 & 0.00 & 0.00 & 0.00 \\
effort in unemp. & 1.25 & 0.20 & $\mathbf{0 . 2 1}$ & 0.22 & 0.22 & 0.22 \\
state $\left(\theta_{\mathbf{b}}\right)$ & 1.75 & 0.33 & 0.37 & $\mathbf{0 . 3 8}$ & 0.39 & 0.39 \\
& 2 & 0.43 & 0.49 & 0.51 & $\mathbf{0 . 5 2}$ & 0.53 \\
& 2 & 0.50 & 0.59 & 0.62 & 0.64 & $\mathbf{0 . 6 5}$
\end{tabular}

NOTE-Panel A shows the implied consumption drop without social insurance for various combinations of risk aversion and disutility of effort to earn income in the bad state for the stylized model in section 4 . The table shows that many combinations of risk aversion and disutility of effort can generate consumption drops similar to those observed in the data (in bold on diagonal). Panel $B$ shows the marginal welfare gains of social insurance for each combination of parameters. Welfare gains are rising on the diagonal even though the consumption drop is constant. 


\section{Figure 1}

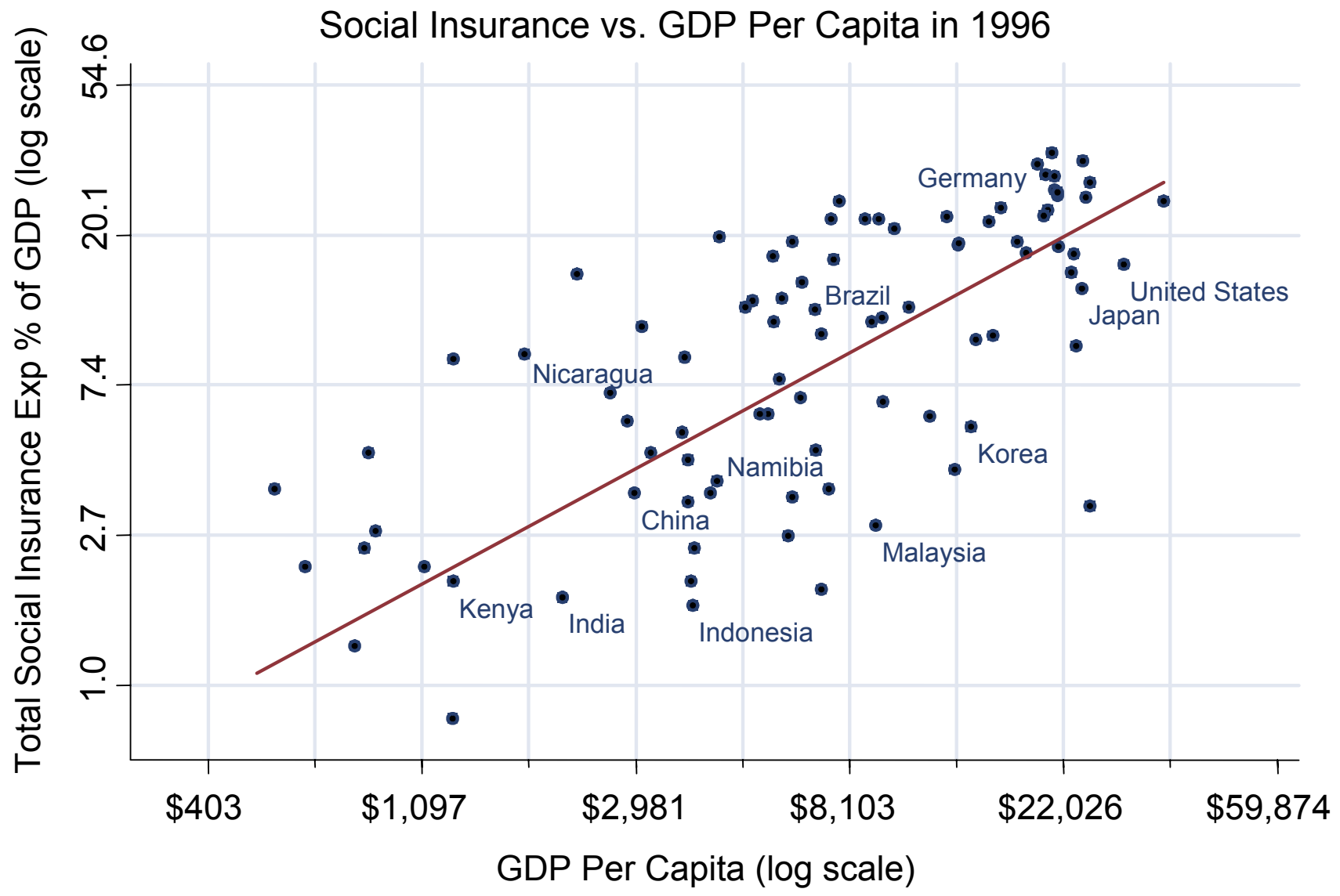

NOTE-Social Insurance statistics are from ILO (2000). Social insurance is defined as total expenditures on social security, disability insurance, unemployment insurance, insurance against work-related injuries, and government provided health insurance. GDP statistics are from the Penn World tables. GDP is measured in PPP-adjusted 1996 US dollars. 